\title{
Wolffian Duct Cell
}

National Cancer Institute

\section{Source}

National Cancer Institute. Wolffian Duct Cell. NCI Thesaurus. Code C43425.

A cell of the embryonic mesonephric duct. This duct connects the primitive kidney and urogenital sinus. In the presence of testosterone, it develops into the sperm collecting apparatus - epididymis, the vas deferens, and seminal vesicles. Without testosterone, it becomes vestigial. 